\title{
PENDIDIKAN SIRAH NABAWIYAH DALAM HUBUNGANNYA DENGAN \\ AKHLAK SISWA DI MTS. AL HIKMAH BANGIL
}

\author{
Iwantoro $^{1}$ \& Dear Rizki Muhajir ${ }^{2}$ \\ STIT Muhammadiyah Bangil \\ 1iwanalfarosi@gmail.com \\ 2Dearrizkimuhajir@gmail.com
}

\begin{abstract}
This study aims to determine the influence of education sirah nabawiyah to morals students in MTs Al-Hikmah Bangil. This study uses quantitative approach and is a population study, because the entire student population of MTs Al-Hikmah Bangil which amounted to 64 students were sampled. The data collection techniques using observation, questionnaires, and documentation. While for the technique of data analysis using statistical formula product moment correlation with the help of SPSS application version 22. From the research and data analysis can be concluded "there is no correlation between sirah nabawiyah education and student morals in MTs Al-Hikmah Bangil based on r product moment $=0.069<r$ table $=0.242$ "so it can be said that there are other variables that have a great contribution to morals students in MTs Al-Hikmah Bangil.
\end{abstract}

Keywords: education sirah nabawiyah, morals students

\section{Pendahuluan}

Pendidikan Islam merupakan salah satu bidang garapan yang sangat penting dalam pembangunan suatu bangsa, karena pembangunan suatu bangsa yang tidak dibarengi dan diiringi pembangunan akhlak, moral, dan etika, maka pembangunan itu tidak akan seimbang, jika pendidikan hanya mementingkan ilmu pengetahuan umum, tanpa diberikan ilmu agama dan penanaman akhlak, maka akan tumbuh generasi yang pintar dan berilmu namun tidak berakhlak. Tidak sedikit dari kalangan generasi muda terpelajar yang setelah mereka sukses mencapai tahap pendidikan tingkat tinggi justru mengalami penurunan kadar keimanan dan keislaman dan menjadi agnostik (tidak peduli agama). Salah satu sebab utama karena yang menjadi inspirator pertama dan utama mereka bukanlah Rasullullah dan para 
sahabat, melainkan dari kalangan tokoh-tokoh non-muslim yang sama sekali tidak memberi suri tauladan perilaku islami (Syuhud, 2015: 9).

Hari ini banyak siswa kita yang mungkin karena gempuran media yang begitu hebat, dengan banyaknya chanel-chanel televisi, internet, dan saranasarana lainnya, menjadikan mereka banyak mengenal bintang-bintang dari dunia artis, pahlawan-pahlawan olah raga dan bintang-bintang televisi. Lalu mereka memberi perhatian besar untuk mencari tahu dan mengikuti informasi-informasi tentang mereka dan bahkan berlomba-lomba untuk segera mengikuti dan meniru mereka. Generasi-generasi yang seperti ini akan menjadikan kehancuran dari suatu bangsa (Al Audah, 2014: 7).

Pendidikan Islam merupakan salah satu aspek dari ajaran Islam secara keseluruhan, karenanya tujuan pendidikan Islam tidak terlepas dari tujuan hidup manusia dalam Islam, yaitu untuk menciptakan pribadi-pribadi hamba Allah Subhanahu Wata'ala, yang selalu bertakwa kepada-Nya dan mencapai kehidupan yang bahagia di dunia dan akhirat (Basuki \& Ulum, 2007: 12). Hal ini diterangkan dalam firman Allah dalam Q.S. Ali Imran ayat 102:

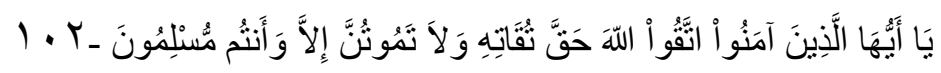

Artinya: "Hai orang-orang yang beriman, bertakwalah kepada Allah sebenar-benar takwa kepada-Nya; dan janganlah sekali-kali kamu mati melainkan dalam Keadaan beragama Islam"(Depag RI, 2009: 63).

Pendidikan Islam sebagaimana diketahui adalah pendidikan yang dalam pelaksanaannya berdasarkan ajaran Islam. Karena ajaran Islam berdasarkan Al Qur'an, as sunnah, pendapat ulama, serta warisan sejarah Nabi Muhammad Salallahu 'alaihi wa sallam (Nata, 2016: 13).

Pendidikan sirah nabawiyah merupakan salah satu upaya agar siswa mendapatkan gambaran sosok ideal dan contoh mulia dalam seluruh aspek kehidupan dalam masalah aqidah, akhlak, dan ibadah yang terdapat dalam diri Nabi Muhammad Salallahu 'alaihi wa sallam. Beliau juga merupakan inspirator pertama dan utama bagi semua umat islam sebelum kita mengambil inspirasi dari siapapun tokoh dunia dan tokoh nasional maupun tokoh lokal yang hidup di zaman sekarang atau di zaman lampau (Syuhud, 
2015: 19). Karena Allah telah menjadikannya qudwah bagi seluruh manusia sebagaimana tercantum dalam Firman Allah dalam Q.S. Al Ahzab ayat 21:

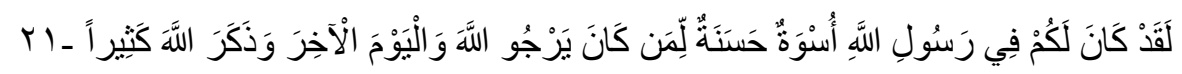

Artinya: "Sungguh, telah ada pada (diri) Rasulullah itu suri teladan yang baik bagimu (yaitu) bagi orang yang mengharap (rahmat) Allah dan (kedatangan) hari Kiamat dan yang banyak mengingat Allah" (Depag RI, 2009: 420).

Rasulullah Salallahu 'alaihi wa sallam merupakan sosok yang langsung dididik oleh Allah, sehingga sudah barang tentu segala tindakan dan perbuatannya mendapat kontrol langsung dari Allah. Jika ada yang kurang benar dalam diri Rasulullah, Allah akan langsung memperingat-kannya, jadi tidak heran jika beliau memiliki akhlak yang paling mulia dan hal itu merupakan tugas beliau diutus oleh Allah Subhanahu wata'ala sebagaimana sabda Rasulullah Salallahu 'alaihi wa sallam dalam riwayat Ahmad yang artinya: "Bahwasannya aku diutus (Allah) untuk menyempurnakan akhlaq" (Nata, 2016: 2).

Oleh karena itu, suatu kelaziman untuk mendididik dan menumbuhkan siswa di atas pendidikan sirah nabawiyah Rasulullah Salallahu 'alaihi wa sallam yang meliputi semua aspek kemanusiaan dalam masyarakat. Ini menjadikan Baginda sebagai contoh teladan yang sangat baik yang harus diikuti oleh siswa sebagai generasi penerus bangsa, baik dalam tindakan maupun perkataan, dan beliau merupakan teladan dalam segala hal (Al Munajjid, 2017: 6).

Kewajiban kita sekarang adalah mengevaluasi kembali metode pendidikan kita dalam mempersiapkan generasi bangsa kita ini, dan memperkenalkan mereka dengan sejarah islam, khususnya sirah Nabi Salallahu 'alaihi wa sallam yang meliputi setiap sudut kemanusiaan yang dimiliki manusia. Ia menceritakan kepada kita perjalanan hidup Nabi Muhammad Salallahu 'alaihi wa sallam selaku pemuda yang amanah dan berakhlak mulia. Jika kita bisa mengemukakan sirah nabawiyah yang berisi kepribadian beliau, akhlak mulia beliau, dan budi perkerti beliau dengan cara 
yang benar kepada siswa kita, niscaya mereka tidak akan mencari teladan selain beliau (Al Audah, 2014: 8).

Membiasakan siswa untuk membaca dan mengajarkan sirah Nabi Muhammad Salallahu 'alaihi wa sallam, para sahabat Rasullullah, para cendikiawan muslim klasik dan modern menjadi kewajiban orang tua dan seluruh edukator muslim baik guru, ustadz, dosen, kyai, habaib, buya, tuan guru, tokoh masyarakat dan lainnya (Syuhud, 2015: 9).

Sekolah merupakan lingkungan pendidikan yang secara sengaja dirancang dan dilaksanakan dengan aturan-aturan ketat seperti harus berjenjang dan berkesinambungan sehingga disebut pendidikan formal (Syaodih, 2004: 164). Demikian juga MTs Al Hikmah Bangil Pasuruan merupakan lembaga pendidikan formal yang berusaha mengedepankan Ilmu Pengetahuan dan Teknologi (IPTEK) serta Iman dan Taqwa (IMTAQ). Berbagai upaya ditempuh demi kemajuan sekolah salah satunya adalah menerapkan pembelajaran sirah nabawiyah Rasulullah Salallahu 'alaihi wa sallam yang diharapkan dengan adanya pemahaman tentang kehidupan Rasullullah Salallahu 'alaihi wa sallam mampu memberikan pengaruh terhadap akhlak siswa.

Kendati demikian, pada observasi awal penulis masih banyak menjumpai siswa yang tidak mengikuti kegiatan pembiasaan sebagaimana yang ditetapkan dan diterapkan oleh pihak madrasah untuk meningkatkan kualitas akhlak dari setiap siswa-siswinya. Di antara bentuk penyimpangan itu adalah sebagian siswa- siswinya masih makan dan minum sambil berdiri, belum membiasakan untuk mengucapkan salam, sholat lima waktu tidak tepat waktu dan lain-lainnya. Di samping itu penulis juga menemukan adanya siswa yang mengucapkan kata-kata kotor dan jorok ketika berbicara, membolos, serta masih dijumpai siswa yang kurang menghormati gurunya.

Dari uraian di atas maka dapat dirumuskan masalahnya adalah sebagai berikut: Adakah pengaruh pendidikan sirah nabawiyah terhadap akhlak siswa di MTs Al-Hikmah Bangil?. Penelitian ini bertujuan untuk: Mengetahui 
adakah korelasi/hubungan pendidikan sirah nabawiyah dengan akhlak siswa di MTs Al-Hikmah Bangil.

\section{Kajian Teori}

\section{Pengertian Akhlak}

Dari segi bahasa akhlak berasal dari kata akhlaqun, bentuk jamak, sedangkan bentuk tunggalnya adalah khuluq yang berarti: perangai atau kelakuan, budi pekerti atau moral, dan kebiasaan atau tabiat (Hadhiri, 2015: 14).

Ibnu Al-Jauzi menjelaskan bahwa al-khuluq adalah etika yang dipilih seseorang. Dinamakan khuluq karena etika bagaikan khalqah (karakter) pada dirinya. Dengan demikian, khuluq adalah etika yang menjadi pilihan dan diusahakan seseorang (Anwar, 2010: 11).

\section{Jenis-Jenis Akhlak}

\section{a. Akhlak Mentauhidkan Allah Subhanahu wata'ala}

Tauhid adalah meyakini keesaan Allah dalam rububiyah, ikhlas beribadah kepada-Nya, menetapkan bagi-Nya nama-nama dan sifatsifat-Nya, serta menyucikan-Nya dari kekurangan dan cacat (Al-Fauzan, 2015: 13). Dengan demikian, tauhid terbagi menjadi tiga macam, yaitu:

1) Tauhid Rububiyah yaitu meyakini bahwa Allah-lah satu-satunya Tuhan yang mencipta alam ini, yang memilikinya, yang mengatur perjalanannya, yang menghidup dan mematikan, yang menurunkan rezeki kepada makhluk, yang berkuasa mendatangkan manfaat dan menimpakan mudarat, yang mengabulkan doa dan permintaan hamba ketika mereka terdesak, yang berkuasa melaksanakan apa yang dikehendakinya, yang memberi dan mencegah, di tangan-Nya segala kebaikan dan bagi-Nya penciptaan dan segala urusan (Anwar, 2010: 90).

2) Tauhid Uluhiyah yaitu mengimani Allah Subhanahu wata'ala sebagai satu-satunya Al-Ma'bud (Anwar, 2010: 90). 
3) Tauhid Asma' dan Sifat yaitu beriman kepada nama-nama dan sifatsifat Allah yang telah Dia tetapkan bagi diri-Nya dalam kitab-Nya ataupun dalam Sunnah Nabi-Nya, tanpa ta'wil, ta'thil, takyif, dan tamsil (Al-Fauzan, 2015: 71).

b. Akhlak Terhadap Al-Qur'an

Al-Qur'an adalah kitab suci yang merupakan sumber utama dan pertama ajaran islam yang menjadi petunjuk kehidupan umat manusia dan diturunkan oleh Allah kepada Nabi Muhammmad Salallahu 'alaihi wa sallam, sebagai salah satu rahmat yang tiada taranya bagi alam semesta" (Al-Qur'an dan terjemahannya, 2009: 102).

Sebagai umat muslim kita harus mempunyai adab atau akhlak terhadap Al-Qur'an yang merupakan kitab suci dan petunjuk bagi umat muslim. Berikut di antara akhlak atau adab kita kepada Al-Qur'an:

1) Mengimani Al-Qur'an

Setiap muslim hendaknya mengimani Al-Qur'an sebagai petunjuk dan pedoman hidup bagi umat muslim, yang di dalamnya tidak ada keraguan sedikit pun. Seperti firman Allah dalam Q.S. Al-Baqarah ayat 2:

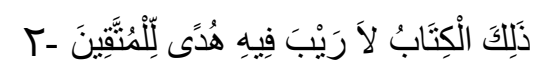

Yang artinya: "Kitab (Al-Qur'an) ini tidak ada keraguan padanya, petunjuk bagi mereka yang bertaqwa" (Hadhiri, 2015: 92).

2) Membaca Al-Qur'an

Setiap mu'min yakin, bahwa membaca Al-Qur'an saja sudah termasuk amal yang sangat mulia dan akan mendapat pahala yang berlipat-ganda, sebab yang dibacanya itu adalah kitab suci. Al-Qur'an adalah sebaik-baik bacaan bagi orang mu'min, baik dikala senang maupun dikala susah, dikala sedih maupun dikala gembira. Membaca Al-Qur'an itu bukan saja menjadi amal dan ibadah, tetapi juga menjadi obat dan penawar bagi orang yang gelisah jiwanya (AlQur'an dan terjemahanya, 2009: 102). 
3) Mempelajari Al-Qur'an

Sebagai seorang mu'min, kita dianjurkan untuk selalu mempelajari dan memahami isi kandungan Al-Qur'an karena Al-Qur'an itu petunjuk dan pedoman kita di dunia. Seperti firman Allah dalam Q.S. Shad ayat 29:

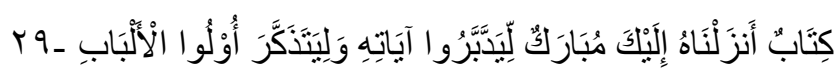

Yang artinya: "Ini adalah sebuah kitab yang Kami turunkan kepadamu penuh dengan berkah supaya mereka memperhatikan ayat-ayat-Nya dan supaya mendapat pelajaran orang-orang yang mempunyai fikiran" (Hadhiri, 2015: 9).

4) Mengamalkan Al-Qur'an

Jika sudah mengerti akan kandungan yang terdapat dalam Al-Qur'an seorang mu'min wajib untuk mengamalkannya dalam kehidupan sehari-hari agar selalu mendapat petunjuk dari Allah (Hadhiri, 2015: 101).

\section{c. Akhlak Terhadap Rasullullah Salallahu 'alaihi wa sallam}

Setiap umat Nabi Muhammad Salallahu 'alaihi wa sallam yang mengakui bahwa Rasullullah adalah utusan Allah, harus mempunyai konsekuensi akhlak kepada beliau, yaitu:

1) Mengimani Kerasulannya

Sebagai umat Nabi Muhammad kita harus meyakini bahwa Rasullullah Salallahu 'alaihi wa sallam merupakan Nabi terakhir yang dipilih oleh Allah dan diutus oleh Allah sebagai pembawa risalah Islam untuk semua umat manusia dan pembawa rahmat untuk seluruh alam. Allah Ta'ala berfirman dalam Q.S. Al-Anbiya' ayat 107:

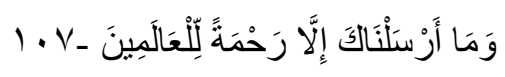

Yang artinya: "Dan Tiadalah Kami mengutus kamu, melainkan untuk (menjadi) rahmat bagi semesta alam" (Hadhiri, 2015: 108). 
2) Mencintai Rasullullah Salallahu 'alaihi wa sallam

Keharusan yang harus kita tunjukkan dalam akhlak yang baik kepada Rasul adalah mencintai beliau dan ahlul baitnya setelah kecintaan kita kepada Allah Subhanahu wata'ala. Sebagaimana Rasulullah bersabda dalam hadist riwayat Bukhari dan Muslim yang artinya: "Tidak beriman salah seorang dari mu, apabila ia tidak mencintaiku melebihi dirinya sendiri, orang tuanya, anaknya, dan manusia semuanya"(Habibah, 2015: 82).

3) Mentaati Dan Mengikuti Rasulullah Sallahu 'alaihi wa sallam

Mentaati dan mengikuti Rasulullah merupakan sesuatu yang bersifat mutlak bagi orang-orang yang beriman kepada beliau. Allah Subhanahu wata'ala akan menempatkan orang-orang yang mentaati Allah dan Rasul-Nya ke dalam derajat yang tinggi dan mulia. Di samping itu juga dicintai Allah Subhanahu wata'ala, sehingga Allah mudah mengampuni dosa orang-orang yang mentaati Allah dan Rasul-Nya. Barang siapa yang mentaati Rasul Salallahu 'alaihi wa sallam berarti juga mentaati Allah Subhanahu wata'ala (Habibah, 2015: 82).

4) Mengucapkan Shalawat Dan Salam Kepada Rasulullah Salallahu 'alaihi wa sallam

Mengucapkan shalawat dan salam kepada Rasulullah merupakan sebagai tanda ucapan terima kasih dan sukses dalam perjuangannya. Rasulullah Salallahu 'alaihi wa sallam juga memerintahkannya seperti dalam sabda beliau riwayat Ahmad yang artinya: "Orang yang kikir ialah orang yang menyebut namaku, tetapi ia tidak bershalawat kepada ku"(Habibah, 2015: 82).

\section{d. Akhlak Terhadap Sesama Muslim}

Islam mengajarkan kepada pemeluknya untuk memiliki akhlak terhadap sesama muslim. Di antara akhlak terhadap sesama muslim adalah 
sebagai berikut: 1) berbuat baik kepada tetangga, 2) suka menolong orang lain, dan 3) suka menasehati.

e. Akhlak Terhadap Keluarga

Sebagai seorang muslim yang baik kita tentu harus mempunyai akhlak kepada keluarga, karena keluargalah orang yang berada dekat dengan kita. Di antara bentuk akhlak terhadap keluarga adalah sebagai berikut: 1) berbakti kepada orang tua, dan 2) bersikap baik kepada saudara.

Demikianlah penjabaran tentang jenis-jenis akhlak yang diharapkan akhlak-akhlak ini telah tertancap di jiwa kita masing-masing sebagai umat muslim yang selalu taat kepada Allah dan Rasul-Nya.

\section{Faktor Yang Mempengaruhi Pembentukan Akhlak}

Peranan penting dalam pembentukan akhlak seseorang siswa tidak boleh diabaikan. Peranan ini dimainkan oleh individu-individu yang signifikan seperti orang tua, teman, sekolah dan guru, serta faktor globalisasi dan media masa. Ke semua faktor-faktor ini memberikan pengaruh yang kuat dalam pembentukan akhlak setiap individu siswa (Stapa, Ismail, dan Yusuf, 2012: 162).

a. Faktor Orang Tua

Berdasarkan kajian yang telah dilakukan oleh Asmah dan Zulekha orang tua memainkan peranan yang cukup penting dalam menangani tingkah laku sosial dalam kalangan remaja. Karena orang tua mempunyai pengaruh yang cukup kuat dalam memberi sumbangan terhadap pembentukan akhlak di kalangan remaja (Stapa, Ismail, dan Yusuf, 2012: 163).

b. Faktor Teman

Teman juga dikenal mempunyai pengaruh yang kuat terhadap proses pembentukan akhlak di kalangan pelajar sekolah. Di sekolah, mereka mula membuat perhubungan dengan rekan di luar lingkungan keluarga. Misalnya: anak yang bergaul dengan teman yang rajin belajar akan 
mendorong perkembangan intelek dan potensinya ke tahap optimum (Stapa, Ismail, dan Yusuf, 2012: 165).

c. Faktor Sekolah Dan Guru

Guru dan sekolah merupakan ejen perubahan dan bersama-sama diberi tugas untuk memperkem-bangkan potensi individu secara menyeluruh dan bersepadu, demi mewujudkan insan yang harmonis dan seimbang dari segi intelek, rohani, akhlak, dan jasmani berdasarkan kepercayaan dan kepatuhan kepada Tuhan (Stapa, Ismail, dan Yusuf, 2012: 166).

d. Faktor Globalisasi Dan Media Massa

Ujian zaman modern yang melanda masyarakat kita hari ini seperti pengaruh media cetak dan elektronik serta kemajuan sains dan teknologi dalam era dunia, telah memburukkan lagi keadaan karena telah menjadikan sejumlah anggota masyarakat kita hilang moral dan akhlak. Sebagai contohnya media sangat berpengaruh terhadap pendidikan, tingkah laku, dan keperibadian anak. Diantaranya adalah TV. TV merupakan satu contoh alat yang banyak mempengaruhi tingkah laku anak-anak. Banyak tingkah laku yang tidak sopan dan agresif ditiru melalui model di dalam suatu acara yang terdapat dalam TV (Stapa, Ismail, dan Yusuf, 2012: 167).

4. Pendidikan Sirah Nabawiyah

a. Pengertian Sirah Nabawiyah

Pengertian sirah nabawiyah menurut Syaikh Shafiyyurrahman AlMubrakfuri adalah ungkapan tentang risalah yang dibawa Rasulullah Shallallahu 'alaihi wa sallam kepada manusia, untuk mengeluarkan mereka dari kegelapan kepada cahaya, dari penyembahan terhadap hamba kepada penyembahan Allah (Al-Mubarakfuri, 2017: 1).

Penulis memberikan kesimpulan tentang pengertian pendidikan sirah nabawiyah yaitu suatu usaha untuk menanamkan sesuatu kepada siswa melalui berbagai kegiatan yang dilakukan secara sadar dan disengaja 
dengan cara mengambil suatu ibrah atau pelajaran yang berasal dari perjalanan hidup dan perjuangan Rasullullah Shallallahu 'alaihi wa sallam dengan harapan siswa mampu menerapkannya dalam kehidupan seharihari.

5. Tujuan Pendidikan Sirah Nabawiyah

Al-Buthy (2010: 2-3) menyebut-kan beberapa tujuan pendidikan sirah nabawiyah yaitu:

a. Memahami pribadi keNabian Rasulullah Shallallahu 'alaihi wa sallam melalui celah-celah kehidupan dan kondisi-kondisi yang pernah dihadapinya, untuk menegaskan bahwa Rasulullah Shallallahu 'alaihi wa sallam bukan hanya seorang yang terkenal genia/ di antara kaumnya, tetapi sebelum itu beliau adalah seorang Rasul yang didukung oleh Allah dengan wahyu dan taufiq dari-Nya.

b. Agar manusia menndapatkan gambaran Al-Matsal Al-Ala (tipe ideal) menyangkut seluruh aspek kehidupan yang utama untuk dijadikan undangundang dan pedoman kehidupannya.

c. Agar manusia mendapatkan pemahaman yang lebih baik dalam mengkaji sirah nabawiyah ini sesuatu yang dapat membawanya untuk memahami kitab Allah dan semangat tujuannya.

d. Melalui kajian sirah nabawiyah ini seorang muslim dapat mengum-pulkan sekian banyak tsaqofah dan pengetahuan Islam yang benar, baik menyangkut aqidah, ibadah ataupun akhlak.

e. Agar setiap pembina dan da'i Islam memiliki contoh hidup menyangkut cara-cara pembinaan dan dakwah.

\section{Sumber-Sumber Sirah Nabawiyah}

Secara umum dapat disebutkan di sini bahwa sumber-sumber dan rujukan sirah nabawiyah ada tiga yaitu: Al-Qur'an, kitab hadist yang shahih, dan perawi yang memiliki perhatian besar terhadap sirah nabawiyah. 
a. Al-Qur'an

Wahyu Allah inilah yang menjadi rujukan utama untuk mengetahui kehidupan Rasullullah Shallallahu 'alaihi wa sallam beserta segala tahapan global perjalanan hidup beliau yang agung. Struktur bahasa Al-Qur'an mengandung banyak petunjuk tentang hal ini (Al-Buthy, 2010: 7).

b. Kitab Hadist Yang Shahih

Kitab-kitab hadist yang ditulis para imam yang kredibilitasnya tidak diragukan lagi, seperti Al-Kutub Al-Sittah (enam kitab hadist) yaitu: kitab Sahih Bukhari, Sahih Muslim, Sunan Abu Daud, Sunan An-Nasai, Sunan AtTirmizi dan Sunan Ibnu Majah. Begitu juga kitab Al-Muwatto' karangan Imam Malik dan Musnad Imam Ahmad. Karena kitab-kitab ini menyoroti ucapan dan perbuatan Rasullullah Shallallahu 'alaihi wa sallam sebagai sumber syari'at, bukan sebagai objek sejarah, tidaklah mengherankan jika tema sentralnya berbau fikih (Al-Buthy, 2010: 7).

c. Perawi Yang Memiliki Perhatian Besar Terhadap Sirah Nabawiyah

Para sahabat banyak yang memiliki perhatian besar terhadap riwayat hidup sang baginda Nabi Muhammad Shallallahu 'alaihi wa sallam. Hampir tidak ada sahabat yang tidak mengetahui sebuah peristiwa atau kejadian tertentu menyangkut Rasul-Iullah Shallallahu 'alaihi wa sallam, tetapi tidak menceritakan kembali peristiwa yang mereka ketahui kepada sahabat lain atau generasi setelah mereka (para tabiin). Namun, pada saat itu, tradisi tersebut tidak mereka imbangi dengan kebiasaan menulis (Al-Buthy, 2010: 7-8).

\section{Metode Penelitian}

Dalam rancangan penelitian ini penulis menggunakan jenis penelitian kuantitatif dengan menggunakan korelasi product moment, karena menghubungkan antara dua variabel. Variabel adalah konsep yang memiliki nilai, atau diartikan sebagai pengelompokan yang logis dari dua atribut atau lebih (Margono, 2009: 133). Jadi variabel penelitian pada dasarnya adalah segala sesuatu yang berbentuk apa saja yang ditetapkan oleh peneliti untuk 
dipelajari sehingga diperoleh informasi tentang hal tersebut, kemudian ditarik kesimpulannya (Sugiyono, 2008: 60).

\section{Populasi Dan Sampel}

Populasi adalah himpunan keseluruhan karakteristik dari objek yang diteliti (Soedarmayanti dan Hidayat, 2002: 121). Menurut Hadari Nawawi populasi adalah keseluruhan objek penelitian yang terdiri dari manusia, benda-benda, hewan, tumbuh-tumbuhan, gejala-gejala, nilai tes, atau peristiwa-peristiwa sebagai sumber data yang memiliki karakteristik tertentu didalam suatu penelitian (Margono, 2009, hal: 118). Populasi dalam penelitian ini adalah seluruh siswa MTs Al-Hikmah Bangil. Adapun jumlah siswa di MTs Al-Hikmah dapat dilihat dalam tabel 3.1 di bawah ini:

Tabel

Jumlah Seluruh Siswa

\begin{tabular}{|c|c|c|c|c|}
\hline \multirow{2}{*}{ NO } & \multirow{2}{*}{ Kelas } & \multicolumn{2}{|c|}{ Jenis kelamin } & \multirow{2}{*}{ Jumlah } \\
\cline { 3 - 5 } & & Laki-laki & Perempuan & \\
\hline 1 & VII & 15 & 10 & 25 \\
\hline 2 & VIII & 9 & 10 & 19 \\
\hline 3 & IX & 12 & 8 & 20 \\
\hline \multicolumn{2}{|r|}{ JUMLAH } & 36 & 28 & 64 \\
\hline
\end{tabular}

Sampel Menurut Suharsimi Arikunto sampel adalah sebagian atau wakil dari populasi yang diteliti (Arikunto, 2006: 131). Apabila subyeknya kurang dari 100, lebih baik diambil semua, tetapi jika jumlah subyeknya lebih dari 100, maka subjek dapat diambil antara 10-15 \%, 20-25 \% atau lebih (Arikunto, 2006: 134). Dari sini penulis mengambil sampel seluruhnya dari jumlah populasi yaitu 64 siswa, dikarenakan jumlah subyeknya kurang dari 100.

\section{Teknik Pengumpulan Data}

Dalam rangka memperoleh data yang berkaitan dengan penelitian ini, maka penulis menggunakan teknik sebagai berikut:

a. Observasi

Teknik ini digunakan untuk memperoleh data tentang letak geografis, sarana dan prasarana, serta kegiatan siswa di MTs Al-Hikmah Bangil. 


\section{b. Angket}

Dalam penelitian ini angket digunakan untuk memperoleh data tentang pendidikan sirah nabawiyah dan akhlak siswa di MTs Al-Hikmah Bangil (Sukmadinata, 2009: 219).

c. Dokumentasi

Metode dokumentasi ini digunakan untuk memperoleh data tentang sejarah berdirinya sekolah, visi-misi dan tujuan, struktur organisasi, keadaan guru-guru, sarana-prasarana dan tentang akhlak siswa di Mts Al-Hikmah Bangil.

\section{Teknik Analisa Data}

Dalam penelitian kuantitatif, analisis data merupakan kegiatan setelah seluruh data dari responden atau dari sumber data lain terkumpul, dengan melakukan perhitungan untuk menjawab rumusan masalah, dan menguji hipotesis yang telah diajukan (Sugiyono, 2008: 207).

Teknik analisis yang digunakan untuk menjawab rumusan masalah ini adalah dengan menggunakan teknis analisis statistik dengan menggunakan statistik korelasi product moment (Widyaningrum, 2009: 111).

$$
r_{x y}=\frac{\frac{\sum x^{1} y^{1}}{N}-C x^{1} C y^{1}}{\mathrm{SD} x^{1} \mathrm{SD} y^{1}}
$$

Keterangan:

$\sum x^{1} y^{1}=$ Jumlah hasil perkalian silang (product moment) antara frekuensi sel (f) dengan $x^{1}$ dan $y^{1}$

$C x^{1}=$ Nilai korelasi pada variable $\mathrm{X}, \mathrm{C} x^{1}=\frac{\Sigma f x^{1}}{N}$

$C y^{1}=$ Nilai korelasi pada variable $\mathrm{Y}, C y^{1}=\frac{\Sigma f y^{1}}{N}$

$\mathrm{SD} x^{1}=$ Defiasi Standart nilai $\mathrm{X}$ dalam arti tiap nilai sebagai 1 unit (dimana $\mathrm{i}=1$ )

$\mathrm{N} \quad=$ Number of class 
4. Hasil Penelitian

Dalam penelitian ini yang dijadikan objek peneliti adalah semua siswa MTs Al-Hikmah Bangil yang berjumlah 64 siswa.

Untuk menganalisis data tentang hubungan pendidikan sirah nabawiyah dengan akhlak siswa di MTs Al-Hikmah Bangil penulis menggunakan teknik perhitungan product moment.

Dalam menghitung data tentang hubungan pendidikan sirah nabawiyah dengan akhlak siswa di MTs Al-Hikmah Bangil penulis menggunakan aplikasi SPSS for windows versi 22, dan hasilnya adalah seperti berikut ini:

\begin{tabular}{|c|c|c|c|}
\hline \multicolumn{4}{|c|}{ Correlations } \\
\hline & & $\begin{array}{c}\text { Sirah_Nab } \\
\text { awiyah }\end{array}$ & $\begin{array}{c}\text { Akhlak_Sis } \\
\text { wa }\end{array}$ \\
\hline \multirow{3}{*}{$\begin{array}{c}\text { Sirah_ } \\
\text { Nabaw } \\
\text { iyah }\end{array}$} & $\begin{array}{l}\text { Pearson } \\
\text { Correlation }\end{array}$ & 1 & -.069 \\
\hline & $\begin{array}{l}\text { Sig. (2- } \\
\text { tailed) }\end{array}$ & & .588 \\
\hline & $\mathrm{N}$ & 64 & 64 \\
\hline \multirow{3}{*}{$\begin{array}{l}\text { Akhlak } \\
\text { _Siswa }\end{array}$} & $\begin{array}{c}\text { Pearson } \\
\text { Correlation }\end{array}$ & -.069 & 1 \\
\hline & $\begin{array}{l}\text { Sig. (2- } \\
\text { tailed) }\end{array}$ & .588 & \\
\hline & $\mathrm{N}$ & 64 & 64 \\
\hline
\end{tabular}

Berdasarkan hasil output di atas dapat disimpulkan bahwa, perhitungan " $r$ " product moment dari data tentang pengaruh pendidikan sirah nabawiyah terhadap akhlak siswa di MTs Al-Hikmah Bangil adalah 0,069. Kemudian nilai ini kita bandingkan dengan nilai $r$ tabel dengan nilai N64 dengan taraf kesalahan $5 \%$ didapat 0,242 . Kesimpulannya, $r$ product moment $=0,069<r$ tabel $=0,242$ artinya pendidikan sirah nabawiyah tidak berkorelasi dengan akhlak siswa di MTs Al-Hikmah Bangil. Sehingga dapat dikatakan ada variabel lain yang memiliki kontribusi lebih besar terhadap akhlak siswa daripada pendidikan sirah nabawiyah. 


\section{Kesimpulan}

Dari uraian deskripsi data dan analisis data dengan menggunakan teknik analisis statistik product moment dalam penelitian ini dapat diambil kesimpulan sebagai berikut:

"Pendidikan sirah nabawiyah tidak berhubungan dengan akhlak siswa di MTs Al-Hikmah Bangil. Berdasarkan perhitungan $r$ product moment $=0,069<r$ tabel $=0,242 "$. Dengan kata lain ada variabel lain yang memiliki kontribusi lebih besar daripada variabel sirah nabawiyah terhadap akhlak siswa di MTs Al-Hikmah Bangil.

\section{DAFTAR PUSTAKA}

Al-Audah, Salman. 2014. Bersama Nabi Sallahu alaihi wassalam. Jakarta: Mutiara Publishing.

Al-Buthy, Said Ramadhan. 2010. Fikih Sirah Hikmah Tersirat Dalam Lintas Sejarah Hidup Rasulullah Salallahu 'alaihi wa sallam. Jakarta Selatan: PT Mizan Publika.

Al-Fauzan, Shalih bin Fauzan. 2015. Kitab Tauhid, Jakarta Timur: Aqwam.

Al-Mubarakfuri, Shafiyyurrahman. 2017. Sirah Nabawiyah Arrakhikul Makhtum. Jakarta Timur: Pustaka Al Kautsar.

Al-Munajjid, Muhammad Shalih. 2017. Cara Nabi Muhammad SAW Memperlakukan Orang di Berbagai Level Sosial. Yogyakarta: Pustaka Pelajar.

Anwar, Rosihon. 2010. Akhlak Tasawuf Edisi Revisi. Bandung: CV Pustaka Setia.

Arikunto, Suharsimi. 2006. Prosedur Penelitian Suatu Pendekatan Praktik refisi VI. Jakarta: PT Rineka Cipta.

At-Tuwaijri, Muhammad bin Ibrahim. 2012. Ringkasan Fiqih Islam. Kerajaan Saudi Arabia: islamhouse.com.

Azra, Azyumardi. 2002. Pendidikan Islam Tradisi dan Modernisasi Menuju Milenium Baru. Jakarta: PT Logos Wacana IImu. 
Basuki dan Ulum, Miftahul. 2007. Pengantar Ilmu Pendidikan Islam. Ponorogo: STAIN Po PRESS.

Constantin. 2012. Urgensi Pendidikan Tauhid Dalam Keluarga. At-Ta'lim, Vol. 3.

Habibah, Syarifah. 2014. Sopan Santun Berpakaian Dalam Islam. JURNAL PESONA DASAR Universitas Syiah Kuala Vol. 2 No.3, Oktober, hal 65-78 ISSN: 2337-9227.

Habibah, Syarifah. 2015. Akhlak Dan Etika Dalam Islam. Pendidikan Guru Sekolah Dasar (PGSD) Universitas Syiah Kuala. JURNAL PESONA DASAR Vol. 1 No.4,Oktober, hal73-87 ISSN: 2337-9227.

Hadhiri, Choiruddin. 2015. Akhlak \& Adab Islami Menuju Pribadi Muslim Ideal. Jakarta: PT Bhuana Ilmu Populer.

Imran, Muhammad. 2013. Wawasan Hadist Rasulullah Shallallahu 'alaihi wa sallam Tentang Menyebarkan Salam. Jurnal Potret Pemikiran Vol. 17. No. 1, Januari-Juni.

Ismail, Ahmad Munawar; Stapa, Zakaria; dan Yusuf, Noranizah. 2012. Faktor Perserikatan Sosial dan Hubungannya Dengan Pembentukan Jati Diri. Jurnal Hadhari Special Edition 155-172.

Khalid, Muhammad Nazir Mohammed. 2016. Bijak Zikrullah, Selangor: Dasar Cetak.

M. Akmansyah. 2014. Metode Pendi-dikan Aqidah Dalam tradisi Propetik Nabi Muhammad Salallahu 'alaihi wa sallam. Jurnal Ijtimaiyya, Vol. 7, No. 1, Februari.

Margono. 2009. Metodologi Penelitian Pendidikan Komponen MKDK. Jakarta: PT Rineka Cipta.

Mulyono. 2012. Strategi Pembelajaran Menuju Efektivitas Pembelajaran di Abad Global. Malang: UIN-Maliki Press.

Musli. 2011. Metode Pendidikan Akhlak Bagi Anak. Fakultas Tarbiyah IAIN Sulthan Thaha Saifuddin Jambi. Media Akademika, Vol. 26, No. 2, April.

Muzakkir. 2015. Keutamaan Belajar Dan Mengajarkan Al-Qur'an: Metode Maudhu'i Dalam Perspektif Hadist. Fakultas Tarbiyah dan Keguruan UIN Alauddin Makassar. LENTERA PENDIDIKAN, VOL. 18 NO. 1 JUNI: 107121. 
Novia, Iva dan Thohir, Mohamad. 2013. Bimbingan Dan Konseling Islam Dengan Terapi Silaturahmi Pada Seorang Remaja Yang Mengalami Depresi. Jurnal Bimbingan dan Konseling Islam Vol. 03, No. 01.

Sakdiah. 2016. Karakteristik Kepemim-pinan Dalam Islam (Kajian Historis Filosofis) Sifat-Sifat Rasulullah. Jurnal Al-Bayan / VOL. 22 NO. 33 JANUARI - JUNI.

Soedarmayanti dan Syarifudin, Hidayat. 2002. Metodologi Penelitian. Bandung: Bandar Maju.

Sohrah. 2016. Etika Makan Dan Minum Dalam Pandangan Syariah. Fakultas Syariah dan Hukum Universitas Islam Negeri (UIN) Alauddin Makassar. Vol. 5 / No. 1 / Juni.

Sudijono, Anas. 2009. Pengantar Evaluasi Pendidikan. Jakarta: PT Raja Grafindo Persada.

Sugiyono. 2008. Metode Penelitian Pendidikan. Bandung: Alfabeta.

Sukmadinata, Nana Syaodih. 2009. Metode Penelitian Pendidikan. Bandung: PT Remaja Rodakarya.

Syamsuddin, Haeriah. 2015. Nabi Muhammad SAW The Real Motivator. Jakarta: PT Bhuana Ilmu Populer.

Syuhud, A.fatih. 2015. Meneladani Akhlak Rasul dan Para Sahabat. Malang: Pustaka Alkhirot.

Usiono. 2017. Potret Rasulullah Sebagai Pendidik. Jurnal ANSIRU Nomor 1 Volume 1, Juni.

Usman, Hussaini dan Purnomo, Setiadi Akbar. 2009. Metodologi Penelitian Sosial. Jakarta: PT Bumi Aksara.

Widyaningrum, Retno. 2009. Statistik Edisi Refisi. Ponorogo: STAINO PO Press.

Wijaya, Tony. 2009. Analisis Data Penelitian Menggunakan SPSS. Yogyakarta: Universitas Atma Jaya. 